\title{
Efeitos do Exploration, Exploitation e Ambidestria no Desempenho das Organizações de Software
}

\author{
The Effects of Exploration, Exploitation, and Ambidexterity on Software Firm \\ Performance
}

Elizandra Severgnini ${ }^{1}$

https://orcid.org/0000-0002-5848-2511

Edwin Vladimir Cardoza Galdamez ${ }^{2}$

https://orcid.org/0000-0002-1763-9332

Valter Afonso Vieira ${ }^{3}$

https://orcid.org/0000-0002-4129-3343

Universidade Federal do Paraná, Programa de Pós-Graduação em Administração, Curitiba, PR, Brasil ${ }^{1}$ Universidade Estadual de Maringá, Programa de Pós-Graduação em Contabilidade, Maringá, PR, Brasil 2 Universidade Estadual de Maringá, Programa de Pós-Graduação em Administração, Maringá, PR, Brasil ${ }^{3}$ 


\title{
Resumo
}

A literatura apresenta lacunas da utilização das competências, recursos e capacidades (exploitation) em conjunto com a exploração de novas competências (exploration) para o alcance do desempenho. Pouco se conhece sobre como as dimensões de exploitation e exploration deveriam ser analisadas, tais como separadamente, por meio de continuum, em sequência, por meio interativo ou por (in)congruência. Dado à ausência de comprovação de como essas duas dimensões podem elucidar a performance, o problema que surge é: Como a congruência das dimensões de ambidestria podem elevar o desempenho? O objetivo do trabalho foi examinar como a congruência entre dualidades afeta o desempenho. Por meio de um levantamento com 227 empresas de software, nós testamos hipóteses relacionadas à congruência e interação dos dois fatores da ambidestria. Os resultados mostraram que (a) as dimensões de exploration e exploitation; (b) a ambidestria média e (c) a ambidestria por meio de um continuum explicam o desempenho, que (d) a interação exploitation $\times$ exploration não tem relação com o resultado da organização e que (e) a convergência de ambas as dimensões aumenta o resultado organizacional. Os achados são coerentes com a tese de Gibson e Birkinshaw (2004) e rejeitam as teses de Gupta, Smith e Shalley (2006) e Cao, Gedajlovic e Zhang (2009).

Palavras-chave: ambidestria; exploration; exploitation; desempenho; capacidades.

\begin{abstract}
The literature presents some shortcomings in the use of current skills, resources, and capabilities (exploitation) with the exploration of new competencies to achieve performance. Little is known about how the dimensions of exploitation and exploration should be analyzed; whether separately, by continuum, in sequence, through interactive or (in) congruence. Given the lack of empirical evidence of how these two dimensions can elucidate performance, the problem that arises is: How can the ambidextrous congruence boost performance? The purpose of the paper was to examine how the congruence between dualities affects organizational performance. Through a survey of 227 software companies, we tested hypotheses related to the congruence and interaction of the two ambidextrous factors. The results showed that (a) the dimensions of exploration and exploitation, average ambidexterity, and ambidexterity by means of a continuum explain the performance; (b) exploitation vs. exploration interaction is not related to the organization's result; and (c) the convergence of both dimensions increases the organizational result. The findings are consistent with the thesis of Gibson and Birkinshaw (2004) and reject the thesis of Gupta, Smith and Shalley (2006) and Cao, Gedajlovic and Zhang (2009).
\end{abstract}

Keywords: ambidexterity; exploration; exploitation; performance; capabilities.

JEL code: L86, G24, L25. 


\section{Introdução}

A ambidestria organizacional (Duncan, 1976; Mom, Chang, Cholakova, \& Jansen, in press) é tradicionalmente aplicada ao estudo da estratégia empresarial (Gibson \& Birkinshaw, 2004; March, 1991), aos sistemas industriais complexos (Takahashi, Bulgacov, Bitencourt, \& Kaynak, 2017) e à gestão da inovação (O'Reilly \& Tushman, 2008, 2013; Tushman \& O'Reilly, 1996). A ambidestria assume que quando os gestores necessitam conquistar os objetivos estratégicos, há necessidade de equilibrar as demandas (ou dualidades) conflitantes entre si em termos de recursos e objetivos (March, 1991) para garantir o sucesso e a sobrevivência no longo prazo (Henri, 2006a; Tushman \& O'Reilly, 1996).

Simons (1995, 2010) observou uma lacuna nas pesquisas em administração quanto à ambidestria organizacional. Especificamente, esta lacuna está direcionada à falta de compreensão sobre a capacidade das organizações de se engajarem simultaneamente na exploração das competências, dos recursos e das capacidades atuais (exploitation) e na exploração de novas competências (exploration) (Simons, 2010) como uma estratégia congruente pela busca de sobrevivência e de melhoria de desempenho (Tushman \& O'Reilly, 1996). Portanto, há uma de falta de compreensão de como o envolvimento simultâneo nesses dois elementos conflitantes podem ajudar a explicar a performance da organização.

Os trabalhos sobre ambidestria organizacional (Ahrens \& Chapman 2004; Cao, Gedajlovic, \& Zhang, 2009; Henri 2006b; Mundy, 2010) demonstram haver gaps de pesquisa descobertos. Primeiro, há falta de trabalhos que analisam os efeitos das dimensões de exploitation e de exploration de modo isolado no desempenho (Ahrens \& Chapman 2004; Mundy 2010; Simons, 2010). Com base em uma análise específica de cada dimensão, as organizações podem compreender qual das duas demandas conflitantes é mais apropriada para seu negócio.

Segundo, Ahrens e Chapman (2004), Brown e Eisenhardt (1997) e Simons (2010) afirmam que há uma notável omissão dos sistemas de controle gerencial por focar demasiadamente no desenvolvimento da eficiência e da eficácia dos recursos organizacionais, sem levar em consideração os diferentes modos de alocar recursos e tarefas com o objetivo simultâneo de exploitation e exploration. Uma forma de resolver esse problema é alocar os recursos de exploitation e exploration de modo conjunto e equilibrado, objetivando alcançar a ambidestria organizacional. Por meio da utilização conjunta dos recursos, as organizações podem expandir a totalidade de suas capacidades (Takahashi et al., 2017) objetivando aumentar o resultado do negócio.

Terceiro, Gupta, Smith e Shalley (2006) e Cao, Gedajlovic e Zhang (2009) sugerem que as duas dimensões de ambidestria deveriam atuar em sinergia e assim poderia haver uma interação entre ambas, amplificando os efeitos no desempenho. Essa interação é defendida teoricamente por Gibson e Birkinshaw (2004) e Hill e Birkinshaw (2014), mas pouco se sabe sobre como funciona empiricamente e sobre como se dá o equilíbrio interativo no uso dos recursos. Por meio da interação, ambas as dimensões teriam efeitos diferentes e complementares, melhorando os resultados. Em tese, o exploration aumentaria o desempenho, se e somente se, o exploitation tiver alto nível.

Quarto, pouco se sabe quanto à sequência das demandas conflitantes que podem explicar o resultado da organização. O pressuposto é de que uma sequência exploitation-->exploration ->desempenho pode ser mais aderente para as empresas de software do que a sequência contrária. Nesse sentido, a literatura prévia (Rothaermel \& Dedds 2004; Venkatraman, Lee, \& Iyer 2006) sugere que há uma sequência especifica que é mais apropriada, mas não há dado empírico de tais opções.

Diante do exposto, nós endereçamos esses quatro gaps e propomos que a ambidestria organizacional influencia o nível de desempenho nas empresas de software. Especificamente, nós buscamos responder o seguinte problema de pesquisa: Como as duas dualidades da ambidestria (de forma congruentes) podem ajudar a elucidar a performance da organização? 
Por meio da pesquisa empírica, nós sugerimos que as empresas com a orientação para o exploitation de recursos, capacidades, atenção e tarefas existentes, concomitantemente com a orientação para o exploration de novos recursos, novas capacidades e novas tarefas (Gibson \& Birkinshaw, 2004; Henri, 2006a; Simons, 2010, 1994) possuem maiores desempenhos. Por fim, nós rejeitamos a tese de Cao et al. (2009) e Gupta et al. (2006), os quais sugerem a ambidestria como um continuum na qual um recurso compete com o outro.

\section{Referencial Teórico}

\section{Ambidestria organizacional}

A ambidestria organizacional foi definida por Duncan (1976) como a capacidade que as organizações possuem de atender demandas simultaneamente conflitantes, de acordo com as habilidades gerenciais desenvolvidas. Estas demandas simultâneas são encontradas na forma de dualidades que são enfrentadas pelos diversos modelos de negócios (March, 1991; Tushman \& O’Reilly, 1996). A Tabela 1 mostra essas investigações.

Tabela 1

\section{Demandas Simultaneamente Conflitantes}

\begin{tabular}{lll}
\hline Autores & Dualidade A & Dualidade B \\
\hline $\begin{array}{l}\text { March (1991); He e Wong (2004); Hill } \\
\text { e Birkinshaw (2014); Simons (2010). }\end{array}$ & Exploitation & Exploration \\
\hline Simons (1991, 1995) & Uso Diagnóstico & Uso Interativo \\
\hline Tushman e O’Reilly (1996) & Mudança Evolutiva & Mudança Revolucionária \\
\hline Henri (2006b) & Cultura voltada controle & Cultura voltada flexibilidade \\
\hline Mundy (2010) & Uso do controle & Uso da estratégia \\
\hline Porter (1986, 1996) & Posicionamento estratégico de & Diferenciação \\
\hline $\begin{array}{l}\text { Adler, Goldoftas e Levine (1999); } \\
\text { Ahrens e Chapman (2004); Jørgensen }\end{array}$ & Eficiência & Flexibilidade \\
e Messner (2009) & & \\
\hline Devinney, Midgley e Venaik (2000) & Integração global & Responsabilidade local \\
\hline Katila e Ahuja (2002) & Profundidade da pesquisa & Escopo da Pesquisa \\
\hline Gibson e Birkinshaw (2004) & Adaptabilidade & Alinhamento \\
\hline Vinekar, Slinkman e Nerur (2006) & Sistemas tradicionais & Sistemas ágeis \\
\hline $\begin{array}{l}\text { Jasmand, Blazevic e Ruyter (2012), } \\
\text { Vieira, Rosa e Faia (2017) }\end{array}$ & Serviços & Provisão de Vendas \\
\hline
\end{tabular}

As organizações devem, por exemplo, tomar decisões que envolvem a aplicação de recursos entre as estratégias da flexibilidade e da eficiência (Adler, Goldoftas, \& Levine's, 1999; Ahrens \& Chapman, 2004); da diferenciação e do baixo custo (Porter, 1996); do uso do controle e da transigência (Mundy, 2010), da adaptabilidade e do alinhamento (Gibson \& Birkinshaw, 2004); da integração global e da responsabilidade local (Devinney, Midgley, \& Venaik, 2000); da exploração de 
novas competências (exploration) e da exploração das competências atuais (exploitation) (He \& Wong, 2004; Hill \& Birkinshaw, 2014; March, 1991; Popadiuk \& Bido, 2016), das inovações incrementais e das revolucionárias (Tushman \& O'Reilly 1996) e do foco nas atividades na prestação de serviços e do foco nas atividades de vendas (Jasmand, Blazevic, \& Ruyter, 2012; Vieira, Rosa, \& Faia, 2017; Yu, Patterson \& Ruyter, 2012).

Para que o gerenciamento dessas demandas conflitantes ocorra, é necessário o balanceamento na aplicação de recursos (Cao et al., 2009; Gupta, Smith, \& Shalley, 2006), de modo que as dualidades - exploration e exploitation - sejam alcançadas simultaneamente, melhorando o desempenho e garantindo a continuidade. Portanto, a organização deve buscar a eficiência, a efetividade e a conformidade (exploitation) e, ao mesmo tempo, implementar a criatividade e a exploração de seus recursos (exploration).

Entre os estudos sobre as demandas conflitantes, um dos mais representativos na literatura de ambidestria organizacional é o de March (1991, p.71), o qual sugere que exploitation e exploration são "atividades de aprendizagem essencialmente diferentes, entre as quais, concorrem com a atenção e com os recursos escassos da empresa". Portanto, as organizações ambidestras são aquelas que demonstram semelhante destreza tanto em atividades de aproveitamento das capacidades atuais (exploitation), quanto em atividades de prospecção de novas competências e exploração de novas oportunidades (exploration) (Simsek, 2009). A Tabela 2 apresenta o entendimento conceitual sobre exploitation e exploration.

Tabela 2

\section{Estrutura Conceitual de Exploitation e Exploration}

\begin{tabular}{lll}
\hline Autores & Exploitation & Exploration \\
\hline March (1991, p.71) & $\begin{array}{l}\text { Integra elementos como o refinamento, } \\
\text { escolha, produção, eficiência, seleção, } \\
\text { implementação e execução e é sintetizada } \\
\text { como "velhas certezas". }\end{array}$ & $\begin{array}{l}\text { Inclui elementos compreendidos em termos } \\
\text { de pesquisa, variação, tomada de riscos, } \\
\text { experimentação, flexibilidade, descoberta e } \\
\text { inovação. Resume como "novas } \\
\text { possibilidades". }\end{array}$ \\
\hline
\end{tabular}

Benner e Tushman Envolve "mudanças incrementais, técnicas (2003, p. 245); Benner e Tushman (2015)

He e Wong (2004) de gestão por processos e de design", explora recursos existentes e atende as pressões de desempenho de curto prazo.
Abrange mudanças radicais, criação e inovação, além de estar voltada para adaptações de desempenho de longo prazo.

\section{Está relacionado com "estruturas mecanicistas, sistemas fortemente conectados, caminhos contínuos, rotinas, controle, burocracia, mercados e tecnologias estáveis" (p. 481). Objetiva a melhoria de mercados e produtos existentes.}

Zimmermann, Envolve a utilização e o compartilhamento Raisch e Birkinshaw do conhecimento existente entre parceiros. (2015, p. 1120)
Está associada com as "estruturas orgânicas, sistema de baixa conexão, novos caminhos, improvisação, autonomia, caos, mercados e tecnologias emergentes" ( $p$. 483). Foca em novos mercados e produtos.

Abrange a criação de novos conhecimentos entre os parceiros envolvidos.

O exploration está relacionado com a capacidade gerencial de criação, inovação, experimentação, gerenciamento de riscos, mudança, flexibilidade, pesquisa e descoberta (March 1991), e o exploitation está associado ao refinamento, à adaptabilidade e à eficiência de produtos ou serviços correntes (Wilden, Hohberger, Devinney, \& Lavie, 2018). O engajamento simultâneo nestes dois grupos de atividades requer diferentes estruturas, estratégias e contextos organizacionais (Raisch \& Birkinshaw, 2008). 
Apesar de existirem diferenças entre as demandas simultaneamente conflitantes, March (1991) propõe que ocorra um equilíbrio entre exploitation e exploration para que uma empresa aumente o desempenho e a competitividade, enquanto alcança o sucesso e a sobrevivência de longo prazo. $\mathrm{O}$ foco demasiado na exploração das capacidades atuais, pode conduzir a organização para um estado de equilíbrio abaixo do ideal, enquanto o foco apenas na conquista de novas capacidades pode envolver altos custos de experimentação, muitas ideias a serem desenvolvidas e poucas competências distintivas (Heavey \& Simsek, 2017). Assim, obter um equilíbrio entre tais atividades distintas que competem entre si por recursos escassos é um fator primordial para a sobrevivência e prosperidade da organização (March, 1991).

Contudo, Cao et al. (2009) e Gupta et al. (2006) oferecem uma visão alternativa na qual o desequilíbrio para uma demanda em detrimento à outra pode fazer a organização ser mais específica e melhorar o desempenho. Portanto, há diferentes modos de estudar as capacidades de exploration e exploitation, os quais este artigo endereça.

\section{Ambidestria organizacional no setor de software}

Empresas de software lidam constantemente com escolhas estratégicas contraditórias, tais como o desenvolvimento de soluções completas para diferentes clientes ou soluções customizadas (Cordeiro, 2014), a necessidade de escolher entre melhorar a eficiência no desenvolvimento de processos ou adaptar as necessidades de novos clientes, decidir sobre adaptação e melhoramento do seu software em relação aos clientes existentes ou explorar novas tecnologias e oportunidades de mercado e, por fim, considerar ambas as inovações como incrementais ou radicais (Napier, Mathiassen, \& Robey, 2011).

Dado o contexto de extrema complexidade, pesquisadores têm buscado compreender como empresas de software lidam com a ambidestria organizacional, conforme trabalhos apresentados na Tabela 3. Por exemplo, Boehm e Turner (2004) encontraram limitações na capacidade das empresas de software alcançarem a ambidestria devido (a) ao foco unicamente no nível de projeto e (b) ao desconhecimento dos efeitos das metodologias ágeis e tradicionais.

Vinekar et al. (2006) sugerem que as empresas criem estruturas separadas a fim de gerar a ambidestria, ponderando a falta de recursos, o conhecimento e a informação como fortes influenciadores da ambidestria. Esses influenciadores também são elementos sugeridos por Katila e Ahuja (2002). Os estudos de Martini (2015) e Tonelli, Zambalde, Brito e Bermejo (2016), por se tratarem de estudos de caso, limitam a generalização das barreiras que dificultam a ambidestria nas indústrias de software. Por fim, Venkatraman, Lee e Iyer (2006), únicos autores que investigaram a dualidade exploitation e exploration, apresentaram evidências de uma relação sequencial no desempenho, na qual a dimensão exploration impacta a dimensão de exploitation que, por sua vez, influencia o desempenho.

Portanto, dado as lacunas levantadas na revisão de literatura, neste artigo nós propomos uma análise mais ampla da relação existente entre a ambidestria organizacional e o desempenho no setor de software, seguindo as sugestões de Gibson e Birkinshaw (2004) e utilizando a congruência. 


\section{Tabela 3}

\section{Estudos de Ambidestria Organizacional no Setor de Software}

\begin{tabular}{|c|c|c|c|c|c|}
\hline Autores / Ano & $\begin{array}{l}\text { Tipo de } \\
\text { Pesquisa }\end{array}$ & Amostra & Objetivos & $\begin{array}{l}\text { Dualidades da } \\
\text { Ambidestria }\end{array}$ & Conclusão \\
\hline $\begin{array}{l}\text { Boehm e } \\
\text { Turner (2004) }\end{array}$ & Qualitativo & 2 empresas & $\begin{array}{l}\text { Examinar aspectos de projetos } \\
\text { relacionados aos métodos ágeis e } \\
\text { disciplinados e prover um abordagem } \\
\text { para balanceá-los. }\end{array}$ & $\begin{array}{l}\text { Agilidade e } \\
\text { Disciplina }\end{array}$ & $\begin{array}{l}\text { Os autores propõem que as características de projetos, tais como: } \\
\text { conjunto de habilidades desenvolvidas; disponibilidade de cliente } \\
\text { e previsibilidade de requisitos são avaliados e usados para guiar a } \\
\text { seleção de um desenvolvimento de processos que melhor se } \\
\text { ajusta a situação. }\end{array}$ \\
\hline $\begin{array}{l}\text { Vinekar et al. } \\
(2006)\end{array}$ & $\begin{array}{l}\text { Discussão } \\
\text { Teórica }\end{array}$ & Não se aplica & $\begin{array}{l}\text { Compreender as razões que levam as } \\
\text { organizações sentirem a necessidade de } \\
\text { conviver com os desafios para sustentar } \\
\text { culturas opostas. }\end{array}$ & $\begin{array}{l}\text { Metodologias } \\
\text { tradicionais e } \\
\text { Metodologias } \\
\text { Ágeis. }\end{array}$ & $\begin{array}{l}\text { Os pesquisadores recomendam que as empresas do setor de } \\
\text { software criem uma subunidade tradicional, focando em } \\
\text { exploitation e uma subunidade ágil, focando em exploration } \\
\text { (Tushman \& O’Reilly, 1996). }\end{array}$ \\
\hline $\begin{array}{l}\text { Venkatraman } \\
\text { et al. (2006) }\end{array}$ & Quantitativo & 1005 empresas & $\begin{array}{l}\text { Testar o impacto da ambidestria no } \\
\text { desempenho de empresas do setor de } \\
\text { software ao longo de um período de } 12 \\
\text { anos. }\end{array}$ & $\begin{array}{l}\text { Exploitation e } \\
\text { Exploration }\end{array}$ & $\begin{array}{l}\text { As evidências sugerem que o equilíbrio sequencial entre } \\
\text { exploitation e exploration, ao longo do tempo, possui efeitos } \\
\text { significativos no desempenho das empresas. }\end{array}$ \\
\hline $\begin{array}{l}\text { Napier, } \\
\text { Mathiassen e } \\
\text { Robey }(2011)\end{array}$ & Qualitativo & 1 empresa & $\begin{array}{l}\text { Desenvolver, aplicar e analisar um } \\
\text { framework que integra a teoria existente } \\
\text { da ambidestria contextual (Gibson \& } \\
\text { Birkinshaw, 2004) com os processos de } \\
\text { coordenação, projeto e inovação para o } \\
\text { aperfeiçoamento das organizações de } \\
\text { software. }\end{array}$ & $\begin{array}{l}\text { Alinhamento e } \\
\text { Adaptabilidade }\end{array}$ & $\begin{array}{l}\text { Os autores propõem que gestores desenvolveram um alto } \\
\text { desempenho contextual e aumentaram a habilidade da } \\
\text { organização de software para alinhar-se e adaptar-se diante das } \\
\text { demandas atuais e futuras de mercado. }\end{array}$ \\
\hline
\end{tabular}


Tabela 3 (continuação)

\begin{tabular}{|c|c|c|c|c|c|}
\hline Autores / Ano & $\begin{array}{l}\text { Tipo de } \\
\text { Pesquisa }\end{array}$ & Amostra & Objetivos & $\begin{array}{l}\text { Dualidades da } \\
\text { Ambidestria }\end{array}$ & Conclusão \\
\hline $\begin{array}{l}\text { Cordeiro } \\
(2014)\end{array}$ & $\begin{array}{l}\text { Quantitativo } \\
\text { e } \\
\text { Qualitativo }\end{array}$ & $\begin{array}{l}466 \text { empresas } \\
\text { (Survey) e } 6 \\
\text { empresas } \\
\text { (Estudo de } \\
\text { caso) }\end{array}$ & $\begin{array}{l}\text { Buscar evidências que possam } \\
\text { comprovar se a escolha da solução } \\
\text { organizacional para a criação da } \\
\text { ambidestria em empresas } \\
\text { desenvolvedoras de software é } \\
\text { influenciada pelas barreiras encontradas } \\
\text { no processo de introdução de uma } \\
\text { metodologia ágil como segunda opção } \\
\text { metodológica. }\end{array}$ & $\begin{array}{l}\text { Metodologias } \\
\text { Ágeis e } \\
\text { Metodologias } \\
\text { Tradicionais }\end{array}$ & $\begin{array}{l}\text { O autor encontrou indícios de que algumas das barreiras } \\
\text { enfrentadas pelas organizações na introdução de metodologias } \\
\text { ágeis, entre elas a diversidade de clientes e de projetos, podem } \\
\text { influenciar a opção das empresas na escolha do tipo de } \\
\text { ambidestria a ser adotado. O estudo apontou também, que } 48,8 \% \\
\text { das empresas que adotaram a prática de metodologias ágeis } \\
\text { praticam a ambidestria. }\end{array}$ \\
\hline Martini (2015) & Qualitativo & 7 empresas & $\begin{array}{l}\text { Investigar quais são os fatores que } \\
\text { impedem grandes empresas de software } \\
\text { de se tornarem ambidestras. Prover } \\
\text { soluções para mitigar tais desafios }\end{array}$ & $\begin{array}{l}\text { Curto Prazo e } \\
\text { Longo Prazo }\end{array}$ & $\begin{array}{l}\text { O estudo apontou três principais desafios que estão dificultando o } \\
\text { alcance da ambidestria: (a) conflito entre metodologias ágeis e } \\
\text { tradicionais; (b) complexidade de equilibrar metas de curto e } \\
\text { longo prazo entre grande número de stakeholders com diferentes } \\
\text { visões e especialidades e (c) a tendência arriscada de desenvolver } \\
\text { sistemas que não se sustentam com uma entrega de longo-prazo } \\
\text { com novas características. O autor propõe uma solução } \\
\text { (CAFFEA) que inclui papéis, times e práticas, as quais são } \\
\text { necessárias por integrar os stakeholders. }\end{array}$ \\
\hline $\begin{array}{l}\text { Tonelli et al. } \\
\text { (2016) }\end{array}$ & Qualitativo & 1 empresa & $\begin{array}{l}\text { Apontar e analisar, sob a perspectiva da } \\
\text { teoria da prática, o processo de } \\
\text { formação de ambidesteridades dentro do } \\
\text { processo de inovação, tendo como } \\
\text { fundamento a constituição mútua entre } \\
\text { ações localizadas e aspectos da cultura. }\end{array}$ & $\begin{array}{l}\text { Ação e } \\
\text { Estrutura }\end{array}$ & $\begin{array}{l}\text { Os resultados apontaram que o processo de construção de } \\
\text { ambidesteridade baseia-se em } 3 \text { estágios: geração de conflitos } \\
\text { iniciais; reação aos conflitos e estabilização via dinâmicas entre } \\
\text { lógicas e ações. }\end{array}$ \\
\hline
\end{tabular}




\section{Hipóteses}

A relação entre ambidestria e desempenho acontece porque há o equilíbrio entre exploitation e exploration, balanceando o foco que a empresa dá nas atividades de criação, inovação, adaptabilidade ao ambiente, em comitente com o alinhamento e a eficiência dos processos correntes (Birkinshaw \& Gupta, 2013; Gibson \& Birkinshaw, 2004). Em uma situação balanceada desses dois elementos, a organização tende a utilizar melhor os seus recursos na conquista de ganhos superiores (Junni, Sarala, Taras, \& Tarba, 2013).

Caso ocorra um desequilíbrio (ou foco excessivo em uma das demandas) pode haver prejuízos e redução de desempenho. Portanto, focar de modo demasiado no alinhamento, na eficiência ou no refinamento em detrimento da criação de novas ideias e inovação pode induzir à estagnação organizacional, impedindo a capacidade da organização de adaptar-se adequadamente às mudanças ambientais e reduzindo a possibilidade que os resultados de desempenho sejam favorecidos no longo prazo (Levinthal \& March, 1993). Do mesmo modo, o foco demasiado na adaptação ao ambiente e na mudança pode ser mais custoso e incerto, o que pode colocar a empresa em risco e prejudicar o desempenho no curto prazo (Karrer \& Fleck, 2015).

Diante do exposto, o processo mais adequado é focar em ambas as capacidades de exploitation e exploration ao mesmo tempo, melhorando o equilíbrio e a congruência estratégica, e gerando resultados de desempenho mais eficazes (He \& Wong, 2004). As atividades de exploitation são importantes para a conquista de resultado financeiro no curto prazo, o que aumenta a capacidade de investimento das empresas nas atividades de exploration. Do mesmo modo, as atividades de exploration geram novos fluxos de receita, os quais, com eficiência podem produzir novos lucros e garantir a continuidade no longo prazo (Karrer \& Fleck, 2015).

Ademais, a ambidestria é especialmente importante em condições de grande dinamismo e incerteza tecnológica e de mercado (O’Reilly \& Tushman, 2013), como é a indústria de software. Neste contexto, as organizações devem procurar novas oportunidades (exploration), uma vez que as atuais vantagens distintivas são incertas e possuem prazos menores de duração, ao mesmo tempo em que devem ser capazes de explorar as oportunidades de forma eficiente e menos custosa (exploitation) (Junni et al., 2013). Portanto, sugere-se que há um efeito positivo da ambidestria organizacional no desempenho das empresas de softwares (Hahn, Pinkse, Preuss, \& Figge, 2016). Logo:

\section{$\mathbf{H}_{1}$ : Há uma relação positiva entre a ambidestria organizacional e o desempenho.}

Ambas as dimensões da ambidestria são condições necessárias para o crescimento e para a continuidade das organizações (Karrer \& Fleck, 2015). A dimensão de exploration é mais relacionada à conquista de resultados no longo prazo e implica em esforços para gerar novas combinações de conhecimento (Andriopoulos \& Lewis, 2009). March (1991, p.71) indica que o exploration está relacionado com a "capacidade gerencial de criação, inovação, experimentação, pesquisa e descoberta". Na indústria do software, o exploration pode ser definido como a criação dos novos produtos, aplicativos, armazenamentos, plataformas e módulos de enterprise resource planning ou business inteligence, ou seja, é uma propensão ao desenvolvimento de inovações radicais (Scandelari \& Cunha, 2013).

No processo de criar novas soluções, as empresas de software tendem a elevar o desempenho, especialmente de longo prazo (Benner \& Tushman, 2003), porque o exploration estabelece novos caminhos para se relacionar com os clientes e está relacionado com as estruturas orgânicas, flexibilidade, autonomia e tecnologias emergentes (Gupta et al, 2006). Portanto, essa ênfase do exploration pode aumentar o tempo de duração dos relacionamentos, e novos fluxos de receita e lucro (Beckman, 2006; Hill \& Birkinshaw, 2014; Lubatkin, Simsek, Ling, \& Veiga, 2006). Logo:

$\mathbf{H}_{2}$ : Há uma relação positiva entre o exploration e o desempenho. 
A dimensão de exploitation é associada à conquista de resultados no curto prazo e implica em "eficiência e pensamento convergente para aproveitar as capacidades atuais e para melhorar continuamente os produtos e serviços atuais" (Andriopoulos \& Lewis, 2009, p. 697). Por meio de suas capacidades atuais, a organização com alto nível de exploitation busca reorganizar, refinar e otimizar a oferta dos seus produtos ou serviços, buscando melhores taxas de retorno dos investimentos no atendimento de clientes e mercados já conquistados (March, 1991; Scandelari \& Cunha, 2013).

Dado que o exploitation envolve "a utilização e o compartilhamento do conhecimento existente entre parceiros" (Zimmermann, Raisch, \& Birkinshaw, 2015, p. 1120) e a readaptação dos produtos ou serviços para os atuais clientes, o exploitation deve aumentar o desempenho porque usa o recurso existente (ex. software já instalado) para oferecer novas soluções e inovações incrementais (ex. upgrades) suficientes para gerar valor aos clientes (Benner \& Tushman, 2003). Em utilizar os recursos existentes, a organização atende de modo ágil e rápido as pressões de desempenho de curto prazo exigidas pelo mercado (Beckman, 2006; Hill \& Birkinshaw, 2014; Lubatkin et al., 2006). Assim:

\section{H3: Há uma relação positiva entre o exploitation e o desempenho.}

As próximas hipóteses buscam examinar as duas teses propostas por Cao et al. (2009) e Gupta et al. (2006), os quais sugerem duas formas de operacionalização das dimensões de exploration e exploitation. A primeira forma é pela multiplicação entre as dimensões e a segunda forma é via subtração de exploration e exploitation.

A primeira forma é a mais usada nos estudos organizacionais (Gibson \& Birkinshaw 2004; Junni et al., 2013; Katila \& Ahuja 2002, Vinekar, Slinkman, \& Nerur, 2006) e tem como pressuposto que a sinergia e o engajamento simultâneo nas dimensões de exploration e exploitation podem ser mensurados pelo produto das duas dimensões (Jasmand et al., 2012; Yu et al., 2012). O pressuposto teórico desta forma de mensuração é que exploration e exploitation são igualmente necessários para atingir a ambidestria organizacional e os seus efeitos no desempenho. Em outras palavras, ambas as dimensões são condições necessárias para a sustentação e crescimento dos negócios devido à sua natureza de complementariedade (Karrer \& Fleck, 2015).

Cao et al. (2009, p.784) argumentam que o "fato da empresa possuir maior ênfase nos esforços de exploitation pode melhorar a competência da empresa em explorar novos conhecimentos e desenvolver novos recursos que suportam novos produtos e mercados". Em compensação, maiores níveis de exploration em um domínio de produto ou tecnologia pode aumentar os esforços de exploitation em um domínio complementar para tornar os novos produtos e tecnologias economicamente viáveis (Gupta et al., 2006). Desse modo, o que se espera é que as organizações demonstrem capacidades dinâmicas para integrar, expandir, construir e reconfigurar recursos e competências internas e externas visando responder rapidamente as demandas do ambiente (O'Reilly \& Tushman, 2013). Portanto, deveria haver uma interação entre as duas dimensões de modo que a sinergia criada aumente a performance. Logo, sugere-se que:

\section{$\mathbf{H}_{4}$ : Há uma relação interativa entre o exploitation e exploration em explicar o desempenho.}

Na segunda forma, subtrai-se uma dimensão da outra conforme sugerem Junni, Sarala, Taras e Tarba (2013). O processo de subtração do exploration de exploitation gera um continuum, conforme proposto por Cao et al. (2009) e Gupta et al. (2006), na qual um extremo é constituído pelo foco na dimensão de exploration e o outro pelo foco na dimensão de exploitation. O ponto central é o estado em que o nível das duas dimensões são equivalentes. Nesse caso não há duas dimensões independentes, mas sim uma única agregada.

O pressuposto teórico para mensurar ambidestria como um continuum é que a decisão entre alocar recursos nas ações de exploration e explotation é um trade-off inevitável e inerente às organizações. Neste caso, a ambidestria organizacional aumenta o desempenho quando encontra um nível ótimo de alocação dos recursos escassos nas duas dimensões (Simsek, Heavey, Veiga, \& Souder, 2009). Portanto, busca-se otimizar o engajamento em exploitation e exploration à procura de um nível ótimo, ou seja, há um efeito quadrático na forma de um U invertido do continuum no desempenho.

RAC, Rio de Janeiro, v. 23, n. 1, art. 6, pp. 111-134, janeiro/fevereiro, 2019, http://rac.anpad.org.br (oc) E 
Analisar a aplicação dos recursos em exploration e exploitation a partir da lógica de concorrência (Boumgarden, Nickerso,n \& Zenger, 2012; Fernhaber \& Patel, 2012; Smith \& Tushman, 2005) pressupõe que há uma relação de dependência entre ambas as demandas (Gupta et al., 2006). Em outras palavras, o continuum exploration-exploitation mensura a competição por recursos escassos, por atenção e por rotinas organizacionais (March, 1991) e assim, quanto mais recursos são usados para exploration, menos recursos são disponibilizados para o exploitation e vice-versa (March, 1991). Uma relação equilibrada é aquela que maximiza o desempenho organizacional e que representa o nível ótimo de aplicação de recursos entre exploitation e exploration, o qual estará entre os dois extremos do continuum. Portanto:

H5: Há uma relação do continuum de exploitation-exploration em explicar o desempenho. Em outras palavras, há um efeito em U invertido do continuum no desempenho.

Venkatraman et al. (2006) sugerem que há um efeito sequencial de exploration-exploitation no crescimento de vendas da organização. A base da argumentação está no fato de que a organização, por pressão de mercado ou de novos clientes, elabora novos softwares e, após vendas e instalação, faz adaptações, atualizações e correções em seus produtos, gerando um exploration em primeiro plano que se transforma em um constante exploitation em segundo momento. Dada a incerteza tecnológica e o dinamismo do ambiente, o exploration é constantemente requerido pelas empresas de software para gerar novas fontes de receita e lucro. As empresas necessitam detectar e aproveitar continuamente novas oportunidades de mercados como forma de expandir e reformular as bases de recursos internos (exploration), as quais, posteriormente serão exploradas conforme a lógica de eficiência (exploration) para se obter melhores níveis de desempenho (Junni et al., 2013; Karrer \& Fleck, 2015; O’Reilly \& Tushman, 2013).

Apesar da sequência exploration ->exploitation já ser conhecida na literatura (Lavie \& Rosenkopf, 2006), os estudos que testaram a relação consideram que as organizações mudam de enfoque ao longo do tempo (O'Reilly \& Tushman, 2013). Em outras palavras, os estudos consideram que as organizações apresentam um enfoque maior em exploration até determinada data e, logo após, o enfoque é redirecionado ao exploitation. Outro modelo de mensuração da ambidestria sequencial foi o adotado por Venkatraman et al. (2006) por meio do produto exploitation ${ }_{(\mathrm{t})} \times$ exploration $_{(\mathrm{t}-1)}$. Neste caso, empresas ambidestras seriam aquelas que no período anterior apresentaram altos níveis de engajamento em exploration seguidos, no período imediatamente seguinte, de altos níveis de engajamento em exploitation.

Contudo, dada nossa argumentação de que as empresas, especialmente aquelas no cenário de incerteza tecnológica, devem ter capacidade de se engajar com a mesma destreza tanto no exploration quanto no exploitation dos recursos. Nós propomos que o exploration leva ao exploitation sem interação, mas via sequência. Portanto, com base em Venkatraman et al. (2006), Rothaermel e Dedds (2004) e Lavie e Rosenkopf (2006), nós sugerimos um modelo mediador em que o envolvimento em exploration influencia o envolvimento em exploitation sem influência do tempo, tendo como consequência final uma melhoria no desempenho. Logo.

$\mathbf{H}_{6}$ : Há uma sequência dos efeitos das capacidades, sendo exploration-->exploitation-$>$ desempenho.

\section{Procedimentos Metodológicos}

\section{Coleta de dados}

Para a coleta de dados foi realizado um levantamento com empresas de software por meio de um questionário estruturado. A população alvo foi limitada às empresas brasileiras desenvolvedoras de software, associadas a algum tipo de entidade do setor ou participante de arranjos produtivos locais. A

RAC, Rio de Janeiro, v. 23, n. 1, art. 6, pp. 111-134, janeiro/fevereiro, 2019, http://rac.anpad.org.br (oc) 
razão por selecionar a população de empresas nacionais do setor de software - que sejam associadas à uma entidade ou participante de uma APL - ocorreu pelo acesso facilitado a essas instituições (população de aproximadamente 2.000 negócios afiliados). O questionário foi encaminhado on-line para a listagem de empresas de software nacionais.

Um protocolo com três etapas foi estabelecido para coleta conforme as recomendações de Henri (2006a). A Etapa 1 foi o envio do e-mail com carta de apresentação e link do questionário. A Etapa 2 foi um envio de lembrete também por e-mail após 3 semanas. A Etapa 3 foi um lembrete por meio de contato telefônico após 6 semanas para as empresas que não retornaram com o questionário respondido.

O questionário deveria ser respondido pelo proprietário ou pelo gestor de projetos da empresa. Portanto, foram incluídas perguntas para controlar o perfil do respondente e o perfil da empresa pesquisada, como seguem: (a) idade; (b) grau de escolaridade; (c) tempo de atuação na empresa; (d) se é proprietário, gestor de projetos ou outro cargo de responsabilidade e que seja apto a responder; (e) porte da empresa e (f) data de fundação da empresa.

\section{Amostra}

O método de seleção da amostra foi o não probabilístico e incluiu a amostragem por conveniência e snowball (Kitchenham \& Pfleeger, 2008). Os critérios para validação dos questionários respondidos foram os seguintes: (a) o respondente é proprietário, gestor de projetos da empresa ou responsável que seja apto a responder, (b) o questionário foi completamente respondido e (c) há consistência nas respostas. Por sua vez, os critérios de exclusão das respostas foram: (a) falhas no preenchimento das respostas, (b) questionário respondido parcialmente e (c) o respondente não é apto a responder o questionário.

No levantamento inicial foram totalizadas 247 empresas respondentes. A análise dos valores ausentes revelou problemas em 20 empresas, as quais foram excluídas da base de dados, resultando em uma amostra final de 227 empresas. Por meio de um levantamento junto a $80 \%$ das associações, arranjos produtivos locais e parques tecnológicos nacionais, estimou-se que a população de empresas desenvolvedoras de software no Brasil é de aproximadamente 2.000 empresas. Portanto, por meio do cálculo amostral para populações finitas é possível estabelecer que a amostra de 227 empresas possui $95 \%$ de grau de confiança para um erro amostral de aproximadamente 6\% (Levine, Berenson, \& Stephan, 2000).

\section{Mensuração das variáveis}

A ambidestria organizacional foi mensurada por meio de uma escala de oito itens, sendo quatro para apurar exploration e outras quatro para mensurar exploitation, adaptados do estudo de $\mathrm{He}$ e Wong (2004). Para mensurar o desempenho organizacional foi adotada uma escala de quatro itens adaptada de Gupta e Govindarajan (1986). Em todas as análises, nós utilizamos a média dos itens. A Tabela 4 apresenta a definição constitutiva e operacional dos construtos. As escalas são do tipo Likert de sete pontos, variando de $1=$ discordo totalmente até $7=$ concordo totalmente. 
Tabela 4

\section{Questionário de Pesquisa}

\begin{tabular}{l}
\hline Indicadores/Questões \\
\hline $\begin{array}{l}\text { Explora1: Há introdução de novos softwares para atender } \\
\text { novos clientes ou novos mercados. }\end{array}$ \\
\hline $\begin{array}{l}\text { Explora2: Há uma grande variedade de software ou serviços } \\
\text { oferecidos. }\end{array}$
\end{tabular}

Explora3: Há abertura de novos mercados a fim de atender novas regiões ou segmentos diferenciados.

\section{Definição conceitual construto}

Esses itens foram projetados para medir o quão importante é para uma empresa realizar projetos de inovação com o intuito de entrar em novos domínios de produtos-mercado (p. e., introduzir um novo software contra melhorar as qualidades existentes do software) (He \& Wong, 2004).

Explora4: Há inserção de novas módulos/ferramentas ou funcionalidades tecnológicas.

Exploita1: Há melhorias no software existente (ex. introdução de novas versões ou atualizações).

Exploita2: Há melhorias na flexibilidade da produção do software.

Exploita3: Há busca por redução dos custos de produção do software.

Exploit4: Há busca por redução do tempo e consumo de material para melhorar o rendimento.

Desempenho1: Em termos de vendas, a empresa está com bom desempenho.

Desempenho2: Em termos de lucro, a empresa está com bom desempenho.

Desempenho3: Há aumento de participação de mercado a cada ano que passa.

Desempenho4: O retorno sobre o investimento possui bom desempenho.
Esses itens foram projetados para medir o quão importante é para a empresa realizar projetos de inovação com o propósito de melhorar as competências existentes e aumentar a eficiência no domínio de mercado-produto (p.e. reduzir o custo de produção em relação a abrir novos mercados) (He \& Wong, 2004).
Esses itens foram projetados com o intuito de medir o desempenho organizacional das empresas desenvolvedoras de software. A escolha por utilizar esta escala se deu porque o "desempenho absoluto de qualquer empresa vai depender não apenas da eficácia da organização interna para a implementação de uma estratégia escolhida, mas também sobre as características do negócio ou do setor e da escolha estratégica em si" (Gupta \& Govindarajan, 1986, p. 704).

Para verificar a validade de conteúdo das escalas e a aderência ao segmento de desenvolvedores de software um painel de especialistas foi elaborado (Okoli \& Pawlowski, 2004). A vantagem da utilização do painel de especialistas ocorre por sustentar escolhas adequadas quanto ao referencial teórico e ao design metodológico (Worrell, Gangi, \& Busch, 2013). Primeiramente, uma busca por especialistas com conhecimentos na área foi feita, a qual resultou na seleção de quatro profissionais. Posteriormente, os questionários foram enviados individualmente para uma pré análise cujo objetivo foi avaliar a terminologia e o entendimento das questões a serem aplicadas nas empresas desenvolvedoras de software.

A partir das sugestões de melhorias e recomendações, o questionário passou pelos primeiros ajustes. Em seguida, o questionário foi novamente apresentado aos especialistas em uma reunião de alinhamento entre os pesquisadores e os especialistas. As sugestões feitas nesta etapa foram adotas no questionário. Após esse processo, o questionário foi encaminhado à amostra. 


\section{Análise dos dados}

Inicialmente, as escalas foram submetidas ao teste de normalidade por meio das medidas de assimetria e curtose (Marôco, 2010). Para tanto, adotou-se o padrão descrito em Kline (1998) de valores de assimetria inferiores a 3,00 e de curtose inferiores à 8,00 . Os maiores valores encontrados foram de 1,09 para assimetria e 5,53 para curtose, os quais permitem pressupor que os dados são não normais e não são problemáticos. Para verificar a confiabilidade das escalas, foi adotada a medida de alfa de Cronbach. Todos os construtos apresentaram valores alfa de Cronbach aceitáveis $(\alpha>0,70)$ (Johnson \& Wichern 2014): $\alpha_{\text {exploration }}=0,71 ; \alpha_{\text {Exploitation }}=0,71$ e $\alpha_{\text {desempenho }}=0,88$.

Para o teste das hipóteses, modelos de regressão múltiplos cuja variável dependente foi o desempenho organizacional foram elaborados. Além da interpretação dos coeficientes de regressão $(\beta)$ e do coeficiente de determinação $\left(\mathrm{R}^{2}\right)$, também foi realizado o exame dos resíduos e dos efeitos da multicolinearidade (Johnson \& Wichern, 2014).

\section{Resultados}

Os principais dados da amostra estão apresentados na Tabela 5. No geral, 48\% dos respondentes são proprietários ou diretores das empresas de software. Entre as opções, a maior concentração de respondentes possui entre 10 e 20 anos de experiência no segmento de software (27\%) e possui ensino superior completo $(40 \%)$.

Tabela 5

\section{Perfil dos Respondentes}

\begin{tabular}{llll}
\hline Níveis de resposta & $\%$ & Níveis de resposta & $\%$ \\
\hline Escolaridade do respondente & & Experiência do respondente & 27,75 \\
Ensino Superior Completo & 40,09 & Entre 10 e 20 anos & 25,56 \\
Especialização & 33,04 & Entre 1 e 5 anos & 25,10 \\
Ensino Superior Incompleto & 13,66 & Entre 5 e 10 anos & 21,15 \\
Mestrado & 5,29 & Mais de 20 anos & 0,44 \\
Ensino Médio Incompleto & 3,52 & Até 1 ano & 48,02 \\
Doutorado & 2,20 & Cargo na empresa & 35,24 \\
Ensino Fundamental Completo & 1,32 & Proprietário/Diretor & 16,74 \\
Ensino Médio Completo & 0,88 & Outros & Gestor de Projetos \\
\hline
\end{tabular}

A Tabela 6 salienta a faixa de faturamento e a idade das empresas de software. Aproximadamente 50\% das empresas têm um faturamento maior que R \$ 2,4 milhões e menor ou igual a R \$ 16 milhões. Sobre a idade das empresas, a distribuição entre as faixas é mais homogênea, no entanto, há maior concentração de empresas com mais de 21 anos de atuação (25\%). As empresas que participaram da pesquisa são de diversos estados do Brasil, contudo os estados de São Paulo (19\%), Santa Catarina (37\%) e Paraná (20\%) totalizaram aproximadamente $77 \%$ da amostra. 
Tabela 6

Faturamento e Dados da Idade das Empresas

\begin{tabular}{lclc}
\hline Níveis de resposta & $\%$ & Níveis de resposta & $\%$ \\
\hline Idade da Empresa & & Porte da empresa (Faturamento Bruto Anual) & \\
Mais de 21 anos & 25,11 & Maior que $\mathrm{R} \$ 2,4$ milhões e <= a R \$ 16 milhões & 49,27 \\
Entre 6 e 10 anos & 21,59 & Maior que $\mathrm{R} \$ 60$ mil e <= à $\mathrm{R} \$ 2,4$ milhões & 27,80 \\
Entre 11 e 15 anos & 18,50 & Maior que $\mathrm{R} \$ 16$ milhões e <= a R \$ 90 milhões & 14,63 \\
Entre 16 e 20 anos & 17,62 & Maior do que $\mathrm{R} \$ 90$ milhões & 6,34 \\
Entre 1 e 5 anos & 17,18 & Faturamento até $\mathrm{R} \$ 60$ mil & 1,95 \\
\hline
\end{tabular}

\section{Teste das hipóteses}

As hipóteses foram testadas com o uso de modelos de regressão, conforme resultados apresentados na Tabela 7. Utilizamos modelos independentes de regressão que não são rivais. No primeiro modelo, foi testado o poder de explicação do desempenho apenas das variáveis de controle. No segundo modelo, adicionou-se a ambidestria organizacional à lista de variáveis independentes, a qual foi operacionalizada pelo produto exploration $\times$ exploitation (similar ao usado em Gibson \& Birkinshaw, 2004; Junni et al., 2013; Vieira et al., 2017). No terceiro modelo, testou-se os efeitos diretos exploration e exploitation no desempenho. No quarto, testou-se o efeito da ambidestria organizacional na forma de um continuum (uma dimensão subtraída da outra) no desempenho (Cao et al., 2009; Gupta et al., 2006). No quinto modelo, testou-se os efeitos diretos de exploration e exploitation, assim como o efeito da interação entre eles no desempenho.

Tabela 7

\section{Resultados da Regressão dos Coeficientes}

\begin{tabular}{|c|c|c|c|c|c|c|c|c|}
\hline Construtos & Model 1 & t-valor & Model 2 & t-valor & Model 3 & t-valor & Model 4 & t-valor \\
\hline Experiência no negócio & $-0,05$ & $-0,47$ & $-0,09$ & $-0,91$ & & & $-0,11$ & $-1,13$ \\
\hline Escolaridade & 0,02 & 0,35 & 0,01 & 0,18 & & & 0,00 & 0,07 \\
\hline Idade da Empresa & $-0,08$ & $-1,23$ & $-0,10$ & $-1,71$ & & & $-0,11$ & $-1,82$ \\
\hline Porte da Empresa & $0,21 * *$ & 3,09 & $0,16^{*}$ & 2,51 & & & $0,17^{*}$ & 2,77 \\
\hline Idade do respondente & $-0,05$ & $-0,47$ & $-0,04$ & $-0,39$ & & & $-0,02$ & $-0,26$ \\
\hline \multicolumn{9}{|l|}{ Preditores } \\
\hline $\mathrm{H}_{1}$ : Ambidestria & & & $0,37 * * *$ & 6,00 & & & & \\
\hline $\mathrm{H}_{2}$ : Exploration & & & & & $0,24 * *$ & 3,27 & $-0,29$ & $-0,94$ \\
\hline $\mathrm{H}_{3}$ : Exploitation & & & & & $0,21 *$ & 2,51 & 0,01 & 0,04 \\
\hline Exploration $^{2}$ & & & & & $-0,06$ & $-1,36$ & & \\
\hline Exploitation $^{2}$ & & & & & 0,08 & 1,10 & & \\
\hline Exploration $\times$ Exploitation & & & & & 0,07 & 1,32 & 0,62 & 1,30 \\
\hline Variance Inflation Factor & 1,46 & & 1,47 & & & 1,90 & 64,05 & \\
\hline Durbin Watson & 2,16 & & 2,08 & & & 2,13 & 2,07 & \\
\hline $\mathrm{R}^{2}$ ajustado & $4 \%$ & & $17 \%$ & & & $14 \%$ & $18 \%$ & \\
\hline
\end{tabular}

Nota. $* p<0,05 ; * * p<0,01 ; * * * p<0,001$.

RAC, Rio de Janeiro, v. 23, n. 1, art. 6, pp. 111-134, janeiro/fevereiro, 2019, http://rac.anpad.org.br (cc)EY 
A primeira hipótese sugere o efeito direto da ambidestria no desempenho. Nós criamos o construto ambidestria por meio da multiplicação das duas dimensões, conforme sugestão de Katila e Ahuja (2002) e Gibson e Birkinshaw (2004). A sugestão da multiplicação tem por base uma literatura que sugere que as dimensões formam um conceito único (Vinekar et al., 2006). Após a criação do construto, nós fizemos a regressão e os resultados mostram que a ambidestria apresenta um efeito positivo no desempenho da organização $(\beta=0,37 ; p<0,001)$, suportando a $\mathrm{H}_{1}$. Desse modo, quanto maior for o envolvimento simultâneo nas atividades de exploration e exploitation, maior será o nível de desempenho da organização (ver modelo 2).

Na sequência, nós examinamos os efeitos diretos de exploration e exploitation no desempenho. Essa sugestão de análise separada por dimensão tem por base uma literatura que defende a ideia das dimensões como elementos isolados (Cao et al., 2009; Gupta et al., 2006). Os resultados demonstram que o exploration $(\beta=0,24 ; p<0,01)$ tem relação com o desempenho, suportando a $\mathrm{H}_{2}$. $\mathrm{O}$ efeito de exploitation foi significativo $(\beta=0,21 ; p<0,05)$ suportando a $\mathrm{H}_{3}$. O resultado salienta que usar os recursos existentes da organização para adaptar produtos ou serviços tem relação com o desempenho (ver modelo 3).

A hipótese 4 tinha por sugestão que as duas dimensões interagissem entre si. Essa ideia tem por base uma literatura que aponta as dimensões criando uma sinergia que pode moderar o impacto no desempenho, amplificando o efeito (Beckman, 2006; Katila \& Ahuja 2002; Lubatkin et al., 2006; Hill $\&$ Birkinshaw, 2014). Contudo, o efeito da interação exploration $\times$ exploitation no desempenho não foi significativo $(\beta=0,62 ; p<0,19)$, não oferecendo suporte a $\mathrm{H}_{4}$. A Figura 1 salienta as inclinações para cada dimensão da ambidestria (ver modelo 4 ).

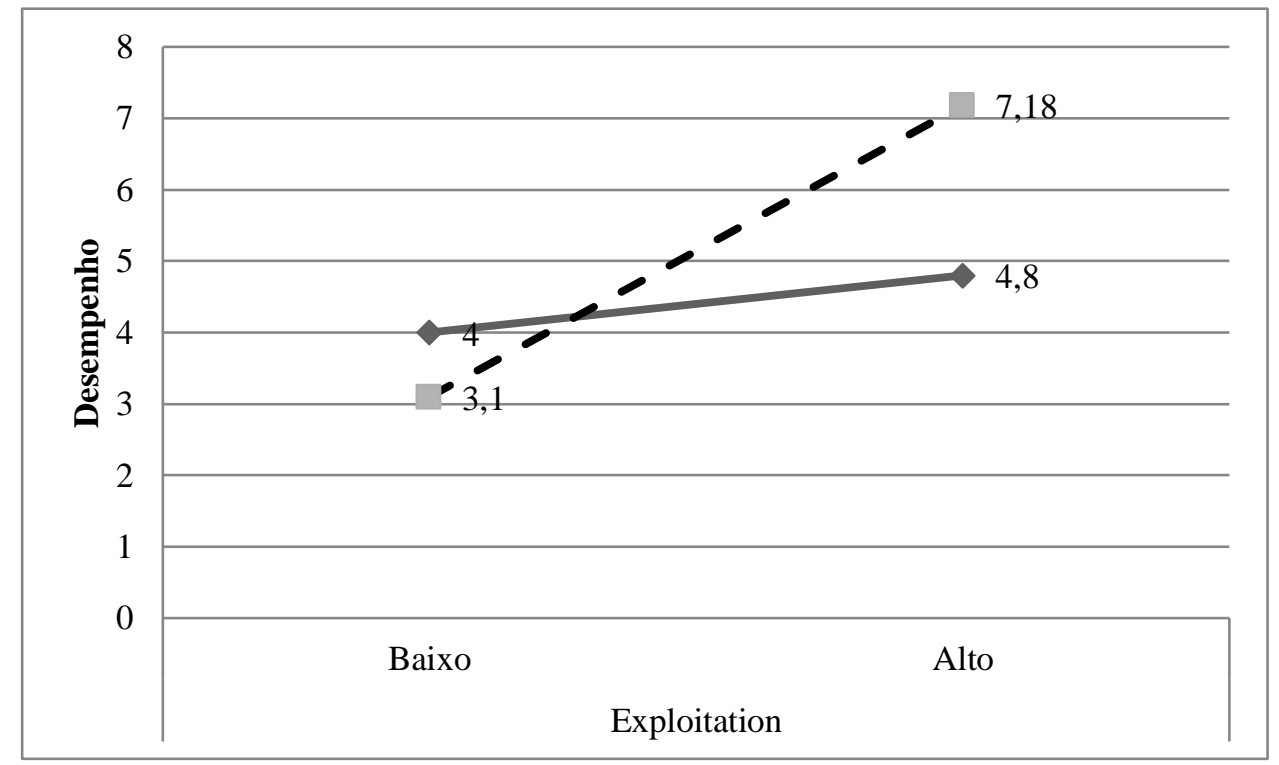

Figura 1. Exploitation $\times$ Exploration como Interação

Legenda: Linha pontilhada denota exploration baixo e linha contínua denota exploration alto.

Na hipótese 5 defendemos o efeito da ambidestria no desempenho mensurado a partir de um continuum (Cao et al., 2009; Marques \& Silveira-Martins, 2017; Silveira-Martins, Rossetto, \& Añaña, 2014). Para tanto, subtraímos os valores de exploration dos valores de exploitation, os quais representam os dois extremos e estratégias que competem entre si em termos de alocação de recursos. Os resultados destacam que o efeito da ambidestria na forma de continuum $(\beta=0,07 ; p=\mathrm{NS})$ não foi significativo, rejeitando a $\mathrm{H}_{5}$. Observa-se que esse efeito não é quadrático, mas sim linear.

Há quatro quadrantes/combinações possíveis para a organização gerar desempenho. Nós fizemos uma análise de cluster pelo método $k$-means e achamos quatro orientações das empresas. $\mathrm{O}$ teste ANOVA indicou diferença significativa para os quatro grupos $(F(3,223)=7,93)$. O grupo com orientação para ambidestria teve a maior média $(M=6,04 ; n=18)$, seguido de exploitation e 
exploration ( $M=4,87 ; n=111$ e $M=4,87 ; n=73$, respectivamente). $\mathrm{O}$ grupo conservador com baixa orientação teve a menor média $(M=4,11 ; n=25)$. Testes post-hoc de Scheffé indicaram a superioridade da ambidestria para com os demais grupos.

Para análise do efeito da congruência, nós usamos o modelo proposto por Edwards e Parry (1993). A congruência e incongruência tanto linear quando quadrática foram estimadas para exploration e exploitation. Espera-se que a congruência entre ambas as dimensões seja mais efetiva do que a incongruência. Para analisar o quanto o desempenho da organização varia em função do nível de congruência, a restrição $Y=X$ foi adicionado à equação 1 , resultando na equação 2 . A soma $b_{1}+b_{2}$ representa a inclinação (slope) da linha de congruência e espera que ela seja significativamente diferente de zero.

$$
\begin{aligned}
& Z=b_{0}+b_{1} X+b_{2} Y+e . \\
& Z=b_{0}+\left(b_{1}+b_{2}\right) X+e .
\end{aligned}
$$

Os resultados demonstram a existência de uma relação linear entre a congruência da exploration e exploitation que é positiva e significativa $\left(b_{1}+b_{2}=0,46 ; p<0,001\right)$. Os resultados não demonstram a existência de uma relação quadrática da congruência $\left(b_{3}+b_{4}+b_{5}=0,08 ; p<0,18\right)$, rejeitando a $\mathrm{H}_{5}$ e as teses de Gupta et al. (2006) e Cao et al. (2009). Ademais, conforme o esperado, os efeitos da incongruência de exploration e exploitation tanto na forma linear $\left(b_{1}-b_{2}=0,03 ; p<0,83\right)$, quanto quadrática $\left(b_{3}-b_{4}+b_{5}=-0,08 ; p<0,54\right)$, não foram expressivos.

$\mathrm{Na}$ hipótese $\mathrm{H}_{6}$, nós propomos uma sequência de efeitos das dimensões no desempenho. Especificamente, propomos que exploration aumenta o exploitation, o qual, por consequência, eleva o desempenho. Para examinar essa hipótese, nós estimamos duas regressões de efeitos indiretos mediados, sendo que na primeira exploitation foi a variável mediadora e na segunda exploration. Esse processo de mediação é similar ao realizado por Faia, Silva e Vieira (2018). Nós esperamos que a primeira sequência tenha efeito indireto mais forte do que a outra, sendo mais aderente ao segmento de software. Os achados confirmaram a $\mathrm{H}_{6}$ e mostram que o impacto indireto na estrutura exploration->exploitation -->desempenho $(\beta=0,14 ; p<0,001)$ é maior do que o efeito indireto na sequência exploitation-->exploration -->desempenho $(\beta=0,08 ; p<0,05)$, embora essa diferença não seja significativa $(\mathrm{Z}=1,07 ; p>0,15)$.

\section{Considerações Finais}

\section{Considerações teóricas}

Três contribuições são encontradas neste trabalho. Primeiro, muitas das pesquisas anteriores não têm considerado simultaneamente a ambidestria organizacional através do exploitation e exploration, o que tem deixado sem resposta inúmeras questões (Gschwantner \& Hiebl, 2016). Nesse gap, o trabalho mostra que as dimensões simultaneamente formam a ambidestria organizacional e melhoram o desempenho. Esse efeito é direto e positivo, o que ajuda a organização a trabalhar nas dualidades de modo conjunto que possui com o objetivo de aumentar as vendas. Esse achado empírico está em linha com Junni et al., (2013) e Gibson e Birkinshaw (2004).

Segundo, a busca por uma dimensão isolada não se mostrou significativa em explicar o desempenho. Esse achado rejeita a tese de Cao et al. (2009), os quais defendem que um recurso competindo com o outro melhora o desempenho dado que a organização pode ter mais foco em um recurso do que em outro. Quando se analisa pela perspectiva da incongruência, ou seja, de uma dimensão mais saliente do que outra, os achados mostraram que o impacto de exploitation sobrepôs e anulou o de exploration, gerando um desequilíbrio entre as tensões ambidestras (He \& Wong, 2004). Ver Figura 2 lado direito comparado ao lado esquerdo. 


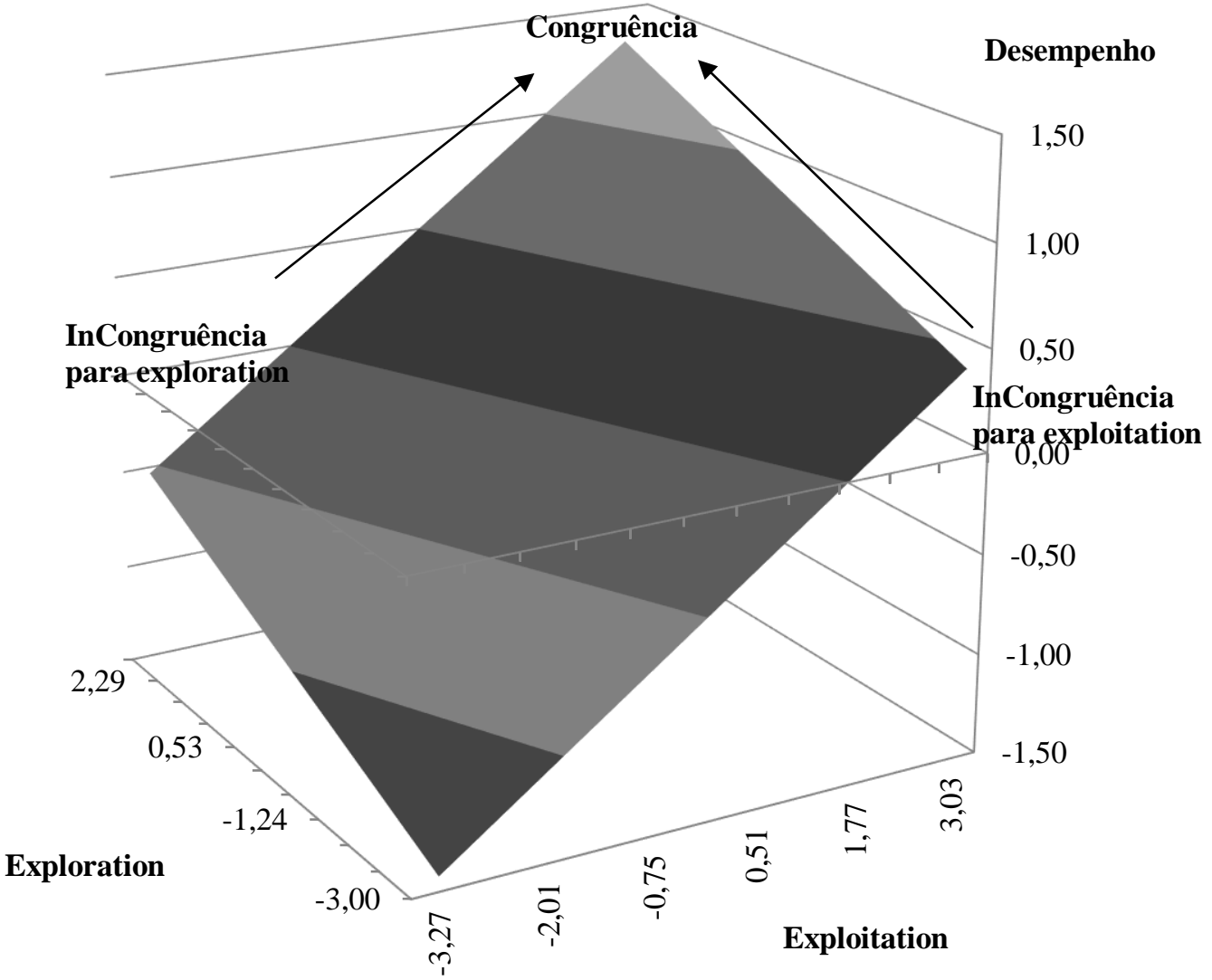

Figura 2. Exploitation e Exploration como congruência linear

Diferentes cores representam as camadas/superfícies

Terceiro, a tese da sequência de qual dimensão é mais aderente à capacidade da organização de software é especulada na literatura (Lavie \& Rosenkopf, 2006; Venkatraman et al., 2006), mas não é testada. Os achados confirmaram a hipótese e mostram que o efeito indireto na sequência exploration-> exploitation no desempenho é mais aderente. Portanto, organizações de software podem obter maiores resultados criando novos produtos e depois adaptando-os para novos mercados.

\section{Considerações práticas}

Para aprimorar os resultados de desempenho, a empresa de software pode focar no processo de implementação da estratégia de exploitation de modo mais acentuado. Gestores das empresas podem ponderar a capacidade da adaptação e reformulação dos módulos e opções de softwares já existentes porque os achados mostram que a dimensão de exploration é a que mais explica o desempenho e tal resultado indica que criar novos produtos, usar recursos para arriscar no mercado e gerar novas soluções de software atendem a aumentar o desempenho da organização.

Embora a dimensão de exploration é mais relevante, os dados também indicam que a congruência de ambas as dimensões (gerando a ambidestria) em realizar duas ações simultâneas (Gibson \& Birkinshaw, 2004), geram benefícios de resultado empresarial. Os resultados mostram que o exploitation de recursos, capacidades, atenção e tarefas existentes, e a exploration de novos recursos, novas capacidades e novas tarefas (Gibson \& Birkinshaw, 2004; Simons, 2010, 1994) quando ambos possuem elevados escores e são coerentes, essas dualidades aumentam o desempenho na forma da ambidestria. 


\section{Limitações e sugestões de pesquisas futuras}

O desempenho organizacional foi mensurado usando informações subjetivas, as quais refletem aos seguintes indicadores: vendas, lucro, participação de mercado e retorno sobre investimentos. Apesar dos testes estatísticos demonstrarem resultados consistentes na mensuração subjetiva, os resultados devem ser interpretados com cuidado, considerando esta limitação e o potencial viés.

Por se tratar de um estudo quantitativo cross-sectional, o trabalho é limitado por não incorporar a evolução da ambidestria e do desempenho organizacional ao longo do tempo. O uso do questionário como ferramenta de pesquisa também possui algumas limitações que podem ter prejudicado a qualidade das respostas, como, por exemplo, o desconhecimento do cenário em que foi respondido.

Futuras pesquisas podem investigar se o uso de um pacote de controles que influenciam positivamente o equilíbrio entre exploration e exploitation ou mesmo a influência de fatores contingenciais, tais como: grau de inovação, cultura organizacional ou incerteza ambiental (Takahashi et al., 2017). Futuras pesquisas podem analisar os efeitos da ambidestria de modo não linear. Ademais, dado o desequilíbrio entre as demandas, a análise balanceada entre as dimensões da ambidestria pode levar em consideração diferença entre os esforços de exploration e exploitation a fim de medir a capacidade de equilíbrio entre as demandas conflitantes (He \& Wong, 2004). Por fim, uma vez que a ambidestria acontece em todos os níveis hierárquicos da empresa, desde um trabalhador da área de produção, até as equipes de call center uma abordagem multinível pode trazer resultados significativos da relação entre os tipos de uso e ambidestria organizacional, conforme recomendação de Birkinshaw e Gupta (2013).

\section{Material Suplementar}

Todos os dados e materiais foram disponibilizados publicamente por meio da plataforma Mendeley e podem ser acessados em: Severgnini, Elizandra (2018), "Data for: THE EFFECTS OF EXPLORATION, EXPLOITATION, AND AMBIDEXTERITY ON SOFTWARE FIRM PERFORMANCE” published by RAC-Revista de Administração Contemporânea”, endeley Data, v1 http://dx.doi.org/10.17632/tgcn93k4w5.1

\section{Contribuições}

$1^{\circ}$ autor: Configuração do artigo - Manuscrito inicial - Construção da revisão de literatura - ajustamento da estrutura do texto - Revisão Final.

$2^{\circ}$ autor: Configuração inicial - Desenvolvimento e alinhamento da revisão de literatura - Ajustamento da estrutura do texto. $3^{\circ}$ autor: Configuração inicial - Desenvolvimento e alinhamento da revisão de literatura - Alinhamento da construção de hipóteses - Análise dos resultados - Revisão Final.

\section{Referências}

Adler, P. S., Goldoftas, B., \& Levine, D. I. (1999). Flexibility versus efficiency? A case study of model changeovers in the Toyota production system. Organization Science, 10(1), 43-68. https://doi.org/10.1287/orsc.10.1.43

Ahrens, T., \& Chapman, C. S. (2004). Accounting for flexibility and efficiency: A field study of management control systems in a restaurant chain. Contemporary Accounting Research, 21(2), 271-301. https://doi.org/10.1506/VJR6-RP75-7GUX-XH0X 
Andriopoulos, C., \& Lewis, M. W. (2009). Exploitation-exploration tensions and organizational ambidexterity: Managing paradoxes of innovation. Organization Science, 20(4), 696-717. http://doi.org/10.1287/orsc.1080.0406

Beckman, C. M. (2006). The influence of founding team company affiliations on firm behavior. Academy of Management Journal, 49(4), 741-758. https://doi.org/10.5465/amj.2006.22083030

Benner, M. J., \& Tushman, M. L. (2015). Reflections on the 2013 decade award - "Exploitation, exploration, and process management: The productivity dilemma revisited" ten years later. Academy of Management Review, 40(4), 497-514. https://doi.org/10.5465/amr.2015.0042

Benner, M. J., \& Tushman, M. L. (2003). Exploitation, exploration, and process management: The productivity dilemma revisited. Academy of Management Review, 28(2), 238-256. https://doi.org/10.2307/30040711

Birkinshaw, J., \& Gupta, K. (2013). Clarifying the distinctive contribution of ambidexterity to the field of organization studies. Academy of Management Perspectives, 27(4), 287-298. https://doi.org/10.5465/amp.2012.0167

Boehm, B., \& Turner, R. (2004, May). Balancing agility and discipline: Evaluating and integrating agile and plan-driven methods. Proceedings of the International Conference on Software Engineering, Edinburgh, UK, 26. https://doi.org/10.1109/ICSE.2004.1317503

Boumgarden, P., Nickerson, J., \& Zenger, T. R. (2012). Sailing into the wind: Exploring the relationships among ambidexterity, vacillation, and organizational performance. Strategic Management Journal, 33(6), 587-610. https://doi.org/10.1002/smj.1972

Brown, S. L., \& Eisenhardt, K. M. (1997). The art of continuous change: Linking complexity theory and time-paced evolution in relentlessly shifting organizations. Administrative Science Quarterly, 42(1), 1-34. https://doi.org/10.2307/2393807

Cao, Q., Gedajlovic, E., \& Zhang, H. (2009). Unpacking organizational ambidexterity: Dimensions, contingencies, and synergistic effects. Organization Science, 20(4), 781-796. https://doi.org/10.1287/orsc.1090.0426

Cordeiro, J. H. D. O. (2014). Ambidestria em empresas desenvolvedoras de software: Barreiras para adoção de metodologias ágeis e seu impacto na escolha do modelo organizacional (Tese de doutorado). Universidade de São Paulo, São Paulo, SP, Brasil.

Devinney, T. M., Midgley, D. F., \& Venaik, S. (2000). The optimal performance of the global firm: Formalizing and extending the integration-responsiveness framework. Organization Science, 11(6), 674-695. https://doi.org/10.1287/orsc.11.6.674.12528

Duncan R. B. (1976). The ambidextrous organization: Designing dual structures for innovation. In R. H. Kilmann, L. R. Pondy, \& D. P. Slevin (Eds.), The management of organization design: Strategies and implementation (Vol. 1, pp. 167-88). New York: North-Holland.

Edwards, J. R., \& Parry, M. E. (1993). On the use of polynomial regression equations as an alternative to difference scores in organizational research. Academy of Management Journal, 36(6), 15771613. http://doi.org/10.5465/256822

Faia. V. da S. , Silva, J. D., \& Vieira, V. A. (2018). A moderação-mediada do sistema de controle na ambidestria. Revista de Administracao Contemporanea, 22(1), 4-22. Recuperado de http://www.scielo.br/pdf/rac/v22n1/1982-7849-rac-22-01-0001.pdf.

http://doi.org/10.1590/1982-7849rac2018160078 
Fernhaber, S. A., \& Patel, P. C. (2012). How do young firms manage product portfolio complexity? The role of absorptive capacity and ambidexterity. Strategic Management Journal, 33(13), 1516-1539. https://doi.org/10.1002/smj.1994

Gibson, C. B., \& Birkinshaw, J. (2004). The antecedents, consequences, and mediating role of organizational ambidexterity. Academy of Management Journal, 47(2), 209-226. https://doi.org/10.5465/20159573

Gschwantner, S., \& Hiebl, M. R. W. (2016). Management control systems and organizational ambidexterity. Journal of Management Control, 27(4), 371-404. https://doi.org/10.1007/s00187-016-0236-3

Gupta, A. K., \& Govindarajan, V. (1986). Resource sharing among SBUs: Strategic antecedents and administrative implications. Academy of Management Journal, 29(4), 695-714. https://doi.org/10.2307/255940

Gupta, A. K., Smith, K. G., \& Shalley, C. E. (2006). The interplay between exploration and exploitation. Academy of Management Journal, 49(4), 693-706. https://doi.org/10.2307/20159793

Hahn, T., Pinkse, J., Preuss, L., \& Figge, F. (2016). Ambidexterity for corporate social performance. Organization Studies, 37(2), 213-235. https://doi.org/10.1177/0170840615604506

He, Z. L., \& Wong, P. K. (2004). Exploration vs. exploitation: An empirical test of the ambidexterity hypothesis. Organization Science, 15(4), 481-494. https://doi.org/10.1287/orsc.1040.0078

Heavey, C., \& Simsek, Z. (2017). Distributed cognition in top management teams and organizational ambidexterity: The influence of transactive memory systems. Journal of Management, 43(3), 919-945. https://doi.org/10.1177/0149206314545652

Henri, J. F. (2006a). Management control systems and strategy: A resource-based perspective. $\begin{array}{llll}\text { Accounting, } \quad \text { Organizations } & \text { Society, }\end{array}$ https://doi.org/10.1016/j.aos.2005.07.001

Henri, J. F. (2006b). Organizational culture and performance measurement systems. Accounting, Organizations and Society, 31(1), 77-103. https://doi.org/10.1016/j.aos.2004.10.003

Hill, S. A., \& Birkinshaw, J. (2014). Ambidexterity and survival in corporate venture units. Journal of Management, 40(7), 1899-1931. https://doi.org/10.1177/0149206312445925

Jasmand, C., Blazevic, V., \& de Ruyter, K. (2012). Generating sales while providing service: A study of customer service representatives' ambidextrous behavior. Journal of Marketing, 76(1), 2037. https://doi.org/10.1509/jm.10.0448

Johnson, R. A., \& Wichern, D. W. (2014). Applied multivariate statistical analysis (Vol. 4). New Jersey: Prentice-Hall.

Jørgensen, B., \& Messner, M. (2009). Management control in new product development: The dynamics of managing flexibility and efficiency. Journal of Management Accounting Research, 21(1), 99-124. https://doi.org/10.2308/jmar.2009.21.1.99

Junni, P., Sarala, R. M., Taras, V., \& Tarba, S. Y. (2013). Organizational ambidexterity and performance: A meta-analysis. Academy of Management Perspectives, 27(4), 299-312. https://doi.org/10.5465/amp.2012.0015

Karrer, D., \& Fleck, D. (2015). Organizing for ambidexterity: A paradox-based typology of ambidexterity-related organizational states. Brazilian Administration Review, 12(4), 365-383. 
Retrieved from http://www.scielo.br/pdf/bar/v12n4/1807-7692-bar-12-04-00365.pdf. http://doi.org/10.1590/1807-7692bar2015150029

Katila, R., \& Ahuja, G. (2002). Something old, something new: A longitudinal study of search behavior and new product introduction. Academy of Management Journal, 45(6), 1183-1194. https://doi.org/10.2307/3069433

Kitchenham B. A., \& Pfleeger S. L. (2008). Personal opinion surveys. In F. Shull, J. Singer, \& D. I. K. Sjøberg (Eds.), Guide to advanced empirical software engineering (pp. 63-92). London: Springer.

Kline, R. B. (1998). Principles and practice of structural equation modeling. New York: Guilford Press.

Lavie, D., \& Rosenkopf, L. (2006). Balancing exploration and exploitation in alliance formation. Academy of Management Journal, 49(4), 797-818. https://doi.org/10.5465/amj.2006.22083085

Levine, D. M., Berenson, M. L., \& Stephan, D. (2000). Estatística: Teoria e aplicações usando Microsoft Excel Português. São Paulo: LTC.

Levinthal, D. A., \& March, J. G. (1993). The myopia of learning. Strategic Management Journal, 14(S2), 95-112. https://doi.org/10.1002/smj.4250141009

Lubatkin, M. H., Simsek, Z., Ling, Y., \& Veiga, J. F. (2006). Ambidexterity and performance in small-to medium-sized firms: The pivotal role of top management team behavioral integration. Journal of Management, 32(5), 646-672. https://doi.org/10.1177/0149206306290712

March, J. G. (1991). Exploration and exploitation in organizational learning. Organization Science, 2(1), 71-87. https://doi.org/10.1287/orsc.2.1.71

Marôco, J. (2010). Análise de equações estruturais: Fundamentos teóricos, software \& aplicações. Pêro Pinheiro, Portugual: ReportNumber, Ltda.

Marques, J. D. L., \& Silveira-Martins, E. (2017). Pressupostos do desempenho: Um estudo da ambidestria, exploração e explotação em uma rede de farmácias do RS. Gestão \& Regionalidade, 33(97). https://doi.org/10.13037/gr.vol33n97.3831

Martini, A. (2015). Ambidexterity in large-scale software engineering (Doctoral dissertation), Department of Computer Science and Engineering, Chalmers University of Technology, Gothenburg, Swedish.

Mom, T. J., Chang, Y. Y., Cholakova, M., \& Jansen, J. J. (in press). A multilevel integrated framework of firm HR practices, individual ambidexterity, and organizational ambidexterity. Journal of Management. https://doi.org/10.1177/0149206318776775

Mundy, J. (2010). Creating dynamic tensions through a balanced use of management control systems. $\begin{array}{llll}\text { Accounting, Organizations and } & \text { Society, }\end{array}$ https://doi.org/10.1016/j.aos.2009.10.005

Napier, N. P., Mathiassen, L., \& Robey, D. (2011). Building contextual ambidexterity in a software company to improve firm-level coordination. European Journal of Information Systems, 20(6), 674-690. https://doi.org/10.1057/ejis.2011.32

O'Reilly, C. A., \& Tushman, M. L. (2008). Ambidexterity as a dynamic capability: Resolving the innovator's dilemma. Research in Organizational Behavior, 28, 185-206. https://doi.org/10.1016/j.riob.2008.06.002 
O’Reilly, C. A., \& Tushman, M. L. (2013). Organizational ambidexterity: Past, present, and future. Academy of Management Perspectives, 27(4), 324-338. https://doi.org/10.5465/amp.2013.0025

Okoli, C., \& Pawlowski, S. D. (2004). The Delphi method as a research tool: An example, design considerations and applications. Information \& Management, 42(1), 15-29. https://doi.org/10.1016/j.im.2003.11.002

Popadiuk, S., \& Bido, D. D. S. (2016). Exploration, exploitation, and organizational coordination mechanisms. Revista de Administração Contemporânea, 20(2), 238-260. Recuperado de http://www.scielo.br/pdf/rac/v20n2/1982-7849-rac-20-2-0238.pdf. http://doi.org/10.1590/19827849rac2016150018

Porter, M.E. (1986). Estratégia competitiva: Técnicas para analisar indústrias e competitividade. Rio de Janeiro: Campus.

Porter, M. E. (1996). O que é estratégia. Harvard Business Review, 74(6), 61-78.

Raisch, S., \& Birkinshaw, J. (2008). Organizational ambidexterity: Antecedents, outcomes, and moderators. Journal of Management, 34(3), 375-381. https://doi.org/10.1177/0149206308316058

Rothaermel, F. T., \& Deeds, D. L. (2004). Exploration and exploitation alliances in biotechnology: A system of new product development. Strategic Management Journal, 25(3), 201-221. https://doi.org/10.1002/smj.376

Scandelari, V. D. R. N., \& Cunha, J. C. D. (2013). Ambidextrality and the socioenvironmental performance of companies in the electro-electronic sector. Revista de Administração de Empresas, 53(2), 183-198. http://doi.org/10.1590/S0034-75902013000200006

Silveira-Martins, E., Rossetto, C. R., \& Añaña, E. S. (2014). Ambidestria, exploração ou explotação e seus efeitos no desempenho organizacional de vinícolas brasileiras. Revista em Agronegócio e Meio Ambiente, 7(3). 16-29.

Simons, R. (1991). Strategic orientation and topo management attention to control systems. Strategic Management Journal, 12(1), 49-62. https://doi.org/10.1002/smj.4250120105

Simons, R. (1994). How new top managers use control systems as levers of strategic renewal. Strategic Management Journal, 15(3), 169-189. https://doi.org/10.1002/smj.4250150301

Simons, R. (1995). Levers of control. Boston, MA: Harvard Business School Press.

Simons, R. (2010). Accountability and control as catalysts for strategic exploration and exploitation: Field study results [Working Paper n ${ }^{\circ}$ 10-051]. Harvard Business School, Boston, MA, USA.

Simsek, Z. (2009). Organizational ambidexterity: Towards a multilevel understanding. Journal of Management Studies, 46(4), 597-624. https://doi.org/10.1111/j.1467-6486.2009.00828.x

Simsek, Z., Heavey, C., Veiga, J. F., \& Souder, D. (2009). A typology for aligning organizational ambidexterity's conceptualizations, antecedents, and outcomes. Journal of Management Studies, 46(5), 864-894. https://doi.org/10.1111/j.1467-6486.2009.00841.x

Smith, W. K., \& Tushman, M. L. (2005). Managing strategic contradictions: A top management model for managing innovation streams. Organization Science, 16(5), 522-536. https://doi.org/10.1287/orsc.1050.0134

Takahashi, A. R. W., Bulgacov, S., Bitencourt, C. C., \& Kaynak, H. (2017). Expanding the dynamic capabilities view: Special contributions. Revista de Administração de Empresas, 57(3), 209214. http://doi.org/10.1590/s0034-759020170302 
Tonelli, A. O., Zambalde, A. L., Brito, M. J., \& Bermejo, P. H. de S. (2016). A teoria da prática e o desenvolvimento de ambidesteridades no processo de inovação em software. Brazilian Business Review, 13(3), 26-49. http://doi.org/10.15728/bbr.2016.13.3.2

Tushman, M. L., \& O’Reilly, C. A. (1996). The ambidextrous organizations: Managing evolutionary and revolutionary change. California Management Review, 38(4), 830. http://doi.org/10.2307/41165852

Venkatraman, N., Lee, C. H., \& Iyer, B. (2006). Strategic ambidexterity and sales growth: A longitudinal test in the software sector. Proceedings of the Annual Meetings of the Academy of Management Meetings, Honolulu, Hawaii.

Vieira, V. A., Rosa, M. A. G, \& Faia, V. S. (2017). A mediação da ambidestria do vendedor na relação entre estresse e desempenho. Revista de Administração Contemporânea, 21(2), 249-268. Recuperado de http://www.scielo.br/pdf/rac/v21n2/1415-6555-rac-21-02-00249.pdf. http://dx.doi.org/10.1590/1982-7849rac2017150339

Vinekar, V., Slinkman, C. W., \& Nerur, S. (2006). Can agile and traditional systems development approaches coexist? An ambidextrous view. Information Systems Management, 23(3), 31-42. https://doi.org/10.1201/1078.10580530/46108.23.3.20060601/93705.4

Wilden, R., Hohberger, J., Devinney, T. M., \& Lavie, D. (2018). Revisiting James march (1991): Whither exploration and exploitation?. Strategic Organization, 16(3), 352-369. https://doi.org/1476127018765031

Worrell, J. L., Di Gangi, P. M., \& Bush, A. A. (2013). Exploring the use of the Delphi method in Accounting Information Systems Research. International Journal of Accounting Information Systems, 14(3), 193-208. https://doi.org/10.1016/j.accinf.2012.03.003

Yu, T., Patterson, P. G., \& Ruyter, K. de (2013). Achieving service-sales ambidexterity. Journal of Service Research, 16(1), 52-66. https://doi.org/10.1177/1094670512453878

Zimmermann, A., Raisch, S., \& Birkinshaw, J. (2015). How is ambidexterity initiated? The emergent charter definition process. Organization Science, 26(4), 1119-1139. https://doi.org/10.1287/orsc.2015.0971

\section{Autores}

Elizandra Severgnini

Av. Prefeito Lothário Meissner, 632, Jardim Botânico, 80210-170, Curitiba, PR, Brasil.

E-mail: elisevergnini@gmail.com

Edwin Vladimir Cardoza Galdamez

Av. Colombo, 5790, Zona 7, 87020-900, Maringá, PR, Brasil.

E-mail: evcgaldamez@uem.br

Valter Afonso Vieira

Av. Colombo, 5790, Zona 7, 87020-900, Maringá, PR, Brasil.

E-mail: valterafonsovieira@gmail.com 